\title{
Evaluation of species transfer models in the cfd simulation of fixed bed soybean drying
}

\author{
Felipe Leonardo Barcelos Mateus ${ }^{1} \mathbb{B}$, Mauro Magalhães Leite Faria ${ }^{2} \mathbb{B}$, Irineu Petri Junior ${ }^{1} \mathbb{B}$
}

${ }^{1}$ Universidade Federal de Lavras/UFLA, Departamento de Engenharia/DEG, Lavras, MG, Brasil

${ }^{2}$ Universidade Federal de Lavras/UFLA, Departamento de Agricultura/DAG, Lavras, MG, Brasil Contact authors: felipe.lb.mateus@gmail.com; mauro.faria@ufla.br; irineu.junior@ufla.br

Received in July 22, 2021 and approved in October 25, 2021

\begin{abstract}
The drying is fundamental to the preservation of materials, particularly food, which is sensible to damaging related to moisture because of its hygroscopic nature. The drying increases the shelf life of these products and reduces their overall weight, which facilitates the logistics and aggregates value to the product. Computational Fluid Dynamics is a potentially facilitating tool for the analysis of drying variables, such as velocity, air temperature, and particle temperature, which have great influence on the drying rate. This work aimed at studying different numeric models for the simulation of a fixed bed drying operation, analyzing the influence of the equilibrium ratio and water diffusivity in the solid on the results. The computations were made in the software FLUENT 19.2, using the Multiphase Eulerian Granular Model with packed bed configuration and different mass transfer models: Constant, Species-Constant, Species-Sherwood, Ranz-Marshall, and Hughmark, as well as heat transfer models: Constant Heat Transfer Coefficient, Constant Nusselt Number, Ranz-Marshall, and Hughmark. The mass transfer models with the best performance were the Ranz-Marshall and Hughmark models. A strong influence of the equilibrium ratio was observed for both models, and a moderate influence of the water diffusivity. The influence of equilibrium ratio and water diffusivity was not observed for the other models. The heat transfer models did not present expressive difference, and the system reached thermal equilibrium quickly. The overall study of the models and the influence of different parameters was effective, and was able to document the obtained results for future optimization and further investigation of the numeric model.
\end{abstract}

Key words: Computational fluid dynamics; Diffusivity; Particle; Eulerian; Mass transfer.

\section{INTRODUCTION}

The drying process is an old industrial operation, and it is responsible for the maintenance of the perishability and moisture equilibrium of materials, preserving them through the induced water evaporation. Drying is specially used in agricultural processes, where products (seeds, cereals, grains) are often higroscopic, that is, have a high capacity for absorbing moisture. Due to that, the process is crucial for the treatment of these products through the moisture reduction. The use of drying is also useful for logistics, as it considerably reduces the weight of the product. However, the operational cost for drying is relatively high (Garcia et al., 2004).

Agricultural products need an extended drying time due to its high moisture content after harvest, and thus the energy consumption per dry product is elevated (Reinato et al., 1991). In order to raise the productivity of the process it is necessary to predict the behaviour of variables that directly affect the quality of the drying and the seeds, related with changes in operational parameters, allowing for the analysis of possible optimizations for the equipment.

In view of that, an alternative to complement the experimental study of drying and for an integral monitoring of the variables in a precise way is through Computational Fluid Dynamics (CFD). This method requires only input data refering to the initial and boundary conditions of the system to calculate the variables through the mass, energy and momentum conservation equations (Xia; Sun, 2002).
The benefits of CFD are only guaranteed through a precise and representative modelling of the real system, integrating the adequate equations and correlations that properly refer to the phenomena of the system. In addition, the numeric model needs to be validated through the comparison of simulated data with experimental data, and their convergence certified (Kloss et al., 2012).

Considering the importance of the subject, other authors also researched on the computational uses in representing the drying process in fixed and fluidized beds. Szafran and Kmiec (2004) simulated a fluidized bed using UDFs (User Defined Functions) to represent the mass and heat transfer, and UDSs (User Defined Scalar) to represent the moisture as a property of the system. They found good results, but the models are not necessarely applicable to fixed beds, considering the use of variables such as particle Reynolds, which would be always null in a fixed regime.

CFD use for a silo-dryer in fixed bed regime was studied by Coradi (2016). The simulations were carried out in bidimensional meshes, and the moisture was not inserted in the numeric model. The removed moisture was subsequently inferred through the energy transfer data obtained by the simulation.

Stoppe (2020) studied experimental and computational experiments in a solar dryer in fixed bed. The meshes used were tridimensional, and the study encompassed the prediction of air velocity profiles considering the bed as a porous media. 
There is a shortage of studies regarding the simulation of fixed bed dryers despite its relevance on elaborating optimizations for the operation. This work aims at developing the subject, using numeric methodologies that are still understudied in the literature, and thus contribute to the study of particles drying simulation.

The objectives of this work were to investigate the general behavior of a fixed bed drying system using various numeric models available in the software FLUENT, notably the models for mass transfer between phases. These are the constant mass transfer model, and the equilibrium ratio model, along with its various sub models: Ranz-Marshall, Hughmark, Sherwood-Number (Species-Sherwood) and constant (SpeciesConstant). In addition, the influence of the equilibrium ratio value for the Species-Constant, Species-Sherwood, Hughmark and Ranz-Marshall models, as well as the influence of water diffusivity for the Species-Constant and Ranz-Marshall models were evaluated. Each model was assessed through comparisons with experimental data from the literature.

\section{MATERIAL AND METHODS}

\subsection{Mathematical Modelling}

The models and equations used in this work for the simulation of the silo-dryer are described in this section. The equations for conservation of mass, energy and momentum were used combined to the Multiphase Eulerian Granular Model to represent the air-particle system. The Species Transfer Model was used for the simulation of mass transfer between the phases. The Species Model is commonly used for the simulation of chemical reactions. However, it can be adapted to represent simply the mass transfer of a substance between phases.
Integrated to the conservation equations, there are the constitutive equations from avaiable models of the solver, FLUENT 19.2. The diagram shown in Figure 1 illustrates the avaible models for heat and mass transfer of the fixed bed silo-dryer, with the here analysed models signaled in green.

For the species mass transfer, besides the Constant, Raoult's Law and Henry's Law, the Equilibrium Ratio model was also used. It requires additional submodels and inputs for the modelling of a phase specific mass transfer constant. These submodels are: Species-Constant, Species-Sherwood, RanzMarshall, and Zero-Resistance.

The Zero-Resistance model was not tested for the solid phase, considering the empirical inconsistency of a mass transfer resistance of zero for a granular solid, which also causes the numeric model to diverge. The models that were not signaled (Species-Constant, Species-Sherwood for the air, and Overall) were not tested to limit the scope of this work, considering the computational cost of the number of simulations.

The models and their respective equations are presented in Table 1. The heat transfer is calculated analogously to Fourier's Law through the difference of temperature between the phases, contact area, and the heat transfer coefficient $(\mathrm{H})$. The heat transfer coefficient can be modelled as a constant value through the correlation for perpendicular flux of air obtained by McCabe (1993) (Equation 1), where G is the flux of air, or through a constant Nusselt number $\left(\mathrm{Nu}_{\mathrm{p}}\right)$ defined by the user for the phase (Equation 2), with its thermal conductivity $\left(\kappa_{q}\right)$ and characteristic diameter $\left(\mathrm{d}_{\mathrm{p}}\right)$. The coefficient can also be calculated varyingly between each cell and through time with the Ranz-Marshall and Hughmark models (Equations 3 and 4, respectively) with the Reynolds $\left(\mathrm{Re}_{\mathrm{p}}\right)$ and Prandtl (Pr) numbers.

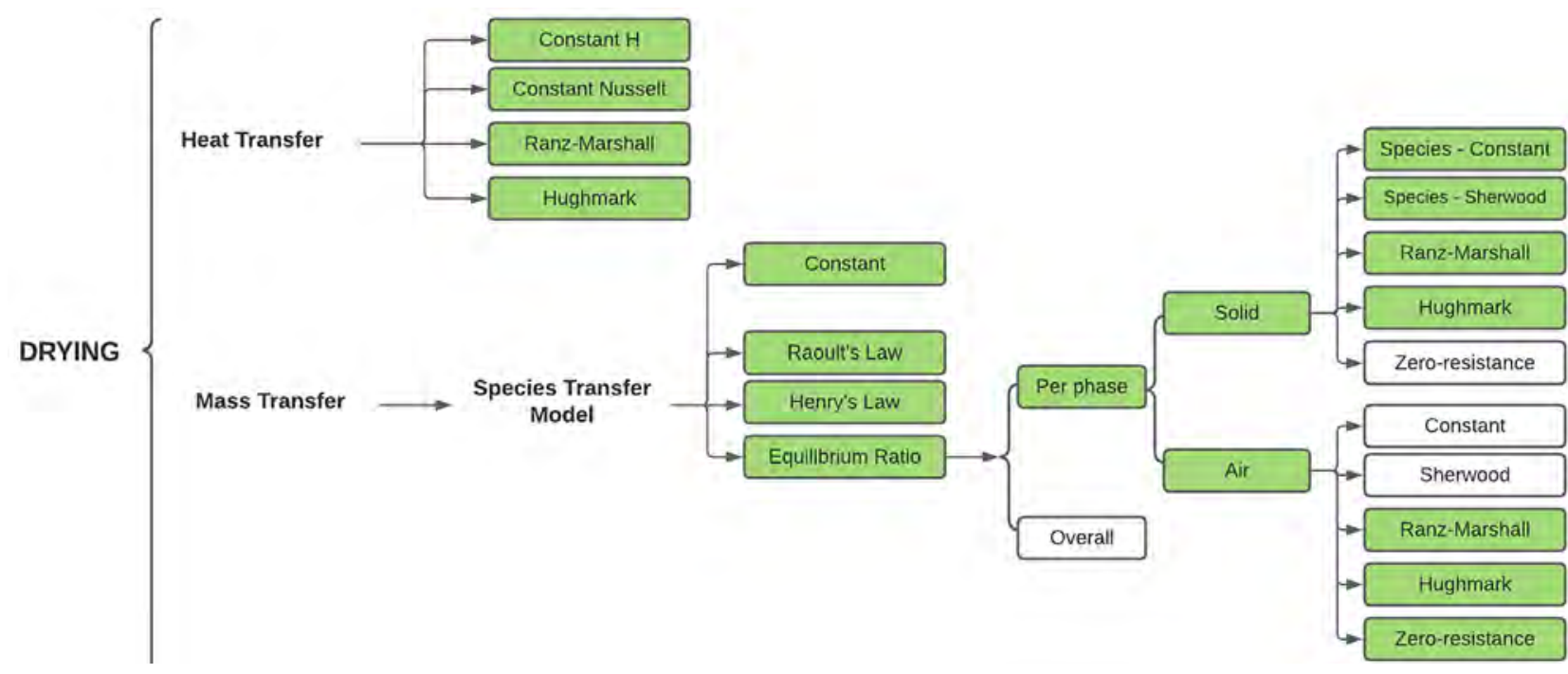

Figure 1: Diagram of the analyzed models. 
The mass transfer can be defined as a constant rate through the definition of a shrinkage rate $(\dot{r})$ with Equation 5 , along with the values of volumetric fraction $\left(\alpha_{\mathrm{p}}\right)$, species mass fraction at phase $\mathrm{p}\left(\mathrm{y}_{\mathrm{p}, \mathrm{i}}\right)$, and density of the phase $\mathrm{p}$ $\left(\rho_{\mathrm{p}}\right)$. Among the equilibrium models, Raoult's Law and Henry's law did not converge to the dryer system. For the Equilibrium Ratio model, the mass transfer is defined by Equation 6, which uses Equations 7 and 8 for its calculus, with the values of the interfacial area $\left(\mathrm{A}_{\mathrm{i}}\right)$, equilibrium ratio $\left(\mathrm{K}_{\text {qipi }}^{\mathrm{p}}\right)$, volumetric mass transfer coefficient $\left(\mathrm{k}_{\mathrm{pq}}\right)$, and solid and air moistures $\left(\mathrm{u}_{\mathrm{s}}\right.$ and $\left.\mathrm{u}_{\mathrm{a}}\right)$.

The Species-Constant model directly defines the phase specific mass transfer coefficient $\left(\mathrm{k}_{\mathrm{q}}\right.$ or $\left.\mathrm{k}_{\mathrm{p}}\right)$, while the Species-Sherwood model defines a constant Sherwood number $\left(\mathrm{Sh}_{\mathrm{p}}\right)$ and the coefficient is calculated through Equation 9, with the value of the species diffusivity $\left(D_{q}\right)$. The Ranz-Marshall and Hughmark models define them locally for each cell through varying values with Equations 10 and 11 respectively, with the Schmidth $\left(\mathrm{Sc}_{\mathrm{p}}\right)$ and Reynolds number.

\subsection{Numerical Methodology}

The computational representation of the equipment was built accordingly to the silo-dryer prototype developed by Coradi and Lemes (2018), which consisted of a cylinder of $1.5 \mathrm{~m}$ in height and $0.2 \mathrm{~m}$ in diameter. The simulations were carried out to all the selected models, and the results were analyzed and compared to the soybean drying experimental results of Coradi et al. (2016), which used the same drying prototype. In it, the grains were disposed in aluminum trays for drying with heated air $(75,90$, and $105^{\circ} \mathrm{C}$ ). To guarantee the comparability, the moisture data used for this work were that of the $90{ }^{\circ} \mathrm{C}$ tests, with an initial moisture of $23 \%$ w.b. to a final moisture of $13 \%$ w.b. However, the drying interval used was that which presented the most constant drying rate behavior, starting at approximately $18 \%$ w.b.

The heat transfer results, however, could not be compared to the experimental data of Coradi et al. (2016), as the grain temperature overtime was not monitored. Still, it was possible to study the influence of different heat transfer model on the temperature of the grains since the behavior between the models was similar.

Table 1: Equations used for the numeric methodology.

\begin{tabular}{ccc}
\hline Model & Equation \\
\hline $\begin{array}{c}\text { Constant Heat Transfer Coefficient - H Constant (McCabe, } \\
\text { 1993) }\end{array}$ & $H=24,2 G^{0,37}$ \\
Constant Nusselt Number & $H=\frac{\kappa_{q} N u_{p}}{d_{p}}$ \\
Ranz-Marshall (1952) & $N u_{p}=2,0+0,6 \operatorname{Re}_{p}^{1 / 2} \operatorname{Pr}^{1 / 3}$ \\
Hughmark (1967) & $0 \leq \operatorname{Re}_{p}<776.06$ & $0 \leq \operatorname{Pr}_{p}<250$ \\
$7 u_{p}=\left\{\begin{array}{c}2+0.6 \operatorname{Re}_{p}^{1 / 2} \operatorname{Pr}_{p}^{1 / 3} \\
2+0.27 \operatorname{Re}_{p}^{0.62} \operatorname{Pr}_{p}^{1 / 3}\end{array}\right.$ & $0 \leq \operatorname{Pr}_{p}<250$
\end{tabular}

Mass Transfer

\begin{tabular}{cc}
\hline Constant Mass Transfer (Constant) & $\dot{m}_{p q}=\dot{r} \alpha_{p} y_{p, i} \rho_{q}$ \\
\hline Equilibrium Models & $\dot{m}_{p q}=k_{p q} A_{i}\left(K_{q i p i}^{p} y_{p, j}-y_{q, i}\right)$ \\
$k_{p q}=\frac{k_{p}+k_{q} K_{q i p i}^{p}}{k_{q} k_{p}}$ & $K_{q i p i}^{\rho}=\frac{u_{s}}{u_{a}}$ \\
\hline Constant Mass Transfer Coefficient (Species-Constant) & $k_{p}=\frac{S h_{p} D_{p}}{L_{p}}$ \\
\hline Sherwood Number (Species-Sherwood) & $S h_{p}=2+0.6 \operatorname{Re}_{p}^{1 / 2} S c_{p}^{1 / 3}$ \\
\hline Ranz-Marshall (1952) & $S h_{p}=\left\{\begin{array}{l}2+0.6 \operatorname{Re}_{p}^{1 / 2} S c_{p}^{1 / 3} \\
2+0.27 \operatorname{Re}_{p}^{0.62} S c_{p}^{1 / 3}\end{array}\right.$ \\
\hline
\end{tabular}


The grains used in the work of Coradi and Lemes (2018) were not identified, to which comes the assumption that a mixture of different grains were used. As the properties of the grains, such as density, specific heat, thermal conductivity, among others, were also not informed, these were obtained by a subsequent work of Coradi and Lemes (2019) as well as other authors (Deshpande; Bal; Ojha, 1993; Azadbakht et al., 2013) using soybeans.

The computational geometry and mesh were constructed in the GAMBIT software, which allowed for the precise construction of cells close to the hexahedral shape. The resulting mesh is shown in Figure 2.

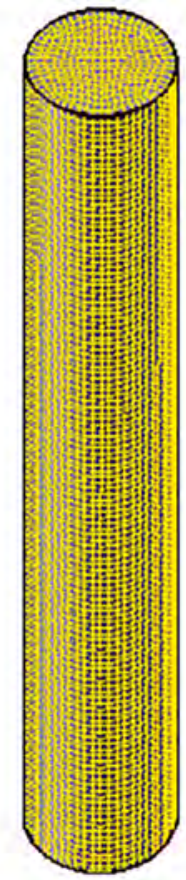

Figure 2: Computational Mesh.

To guarantee the representativeness of the mesh, the mesh independence test was made. The initial number of cells was of 210,734 , which was modified to other three similar meshes of $80,640,384,079$ and 717,120 cells. The test was made using the Constant model, monitoring the moisture over time between the different meshes.

The simulations were configured using the physical properties defined in Table 2 through values obtained in the literature. The initial and boundary conditions, numerical models, and numeric parameters are presented in Table 2. The mass transfer coefficient was calculated through the drying experimental curve from the work of Coradi et al. (2016). The moisture must be defined in wet basis, as the property is defined by the software as mass fraction. The air moisture was not specified in the work of Coradi et al. (2016), so its value was stipulated as the ideal value of zero. The same was true for the pressure at the air outlet, which was defined here as 101,325 $\mathrm{Pa}$.
The mass transfer coefficient for the solid phase, equilibrium ratio, and heat transfer coefficient were calculated through the equations in Table 3. The constant Sherwood number was calculated through Equation 10.

The influence of the equilibrium ratio $\left(\mathrm{K}_{\text {qipi }}^{\mathrm{p}}\right)$ was observed for the simulations using the Equilibrium Ratio model (Species-Constant, Species-Sherwood, Ranz-Marshall, and Hughmark). This was relevant due to the direct relation of the parameter to the varying moisture values of the phases.

The equilibrium ratio values of 0.1558 and 1,558.565 were used for the Species-Sherwood and Species - Constant models, and 1,558.565 and 15,585.65 for the Ranz-Marshall and Hughmark models. The chosen values were deliberately extreme to better observe their influence on the results.

Additionally, for the models Ranz-Marshall and Species-Constant, four additional values of the water diffusivity in the solid were tested, considering its influence on the mass transfer resistance of the solid phase as observed in Equation 9. The values used were: $10^{-9}$ and $10^{-11} \mathrm{~m}^{2} / \mathrm{s}$, common values for agricultural products (Madamba; Driscoll; Buckle, 1996), and, additionally, $10^{-13}$ and $10^{-25} \mathrm{~m}^{2} / \mathrm{s}$. There was no substantial difference between the values of $10^{-9}, 10^{-11}$, and $10^{-}$ ${ }^{13} \mathrm{~m}^{2} / \mathrm{s}$, thus, the value used for all the other simulations was $10^{-13} \mathrm{~m}^{2} / \mathrm{s}$, which showed faster numerical convergence.

\section{RESULTS}

\subsection{Mesh Independence Test}

The mesh independence test was made using the meshes of 80,640, 210,734, 384,079, and 717,120 cells, using the Constant model for the mass transfer. The solid moisture, variable of interest, for the four meshes over time can be observed in Figure 3.

\subsection{Heat Transfer}

The four different modellings for the heat transfer were tested to analyze their effects on the heating of the particles. The temperature results over time for four models are presented in Figure 4.

\subsection{Mass Transfer}

\subsubsection{Constant, Species-Constant and Species- Sherwood models}

In this section the moisture results for three models: constant drying rate (Constant), constant mass transfer coefficient (Species-Constant), constant Sherwood number (Species-Sherwood) will be analyzed. The Species-Constant and Species-Sherwood models are part of the Equilibrium Ratio model, just as the Hughmark and Ranz-Marshall models. 
Table 3: Physical properties of soybeans.

\begin{tabular}{ccc}
\hline \multicolumn{2}{c}{ Properties of the solid } & Reference \\
\hline Density $(\rho)$ & $791.21 \mathrm{~kg} / \mathrm{m}^{3}$ & (Deshpande; Bal; Ojha, 1993) \\
Specific heat $\left(\mathrm{c}_{\mathrm{p}}\right)$ & $1856 \mathrm{~J} / \mathrm{kg} \mathrm{K}$ & (Azadbakht et al., 2013) \\
Thermal conductivity $(\mathrm{k})$ & $0.038 \mathrm{~W} / \mathrm{m} \mathrm{K}$ & (Azadbakht et al., 2013) \\
Particle diameter $\left(\mathrm{d}_{\mathrm{p}}\right)$ & $0.01 \mathrm{~m}$ & (Coradi; Lemes, 2019) \\
Packing limit $(\varepsilon)$ & 0.5236 & (Coradi; Lemes, 2019) \\
Water diffusivity in the solid & $110^{-13} \mathrm{~m}^{2} / \mathrm{s}$ & (Bergman et al., 2011) \\
Water diffusivity in the air & $2.6010^{-5} \mathrm{~m}^{2} / \mathrm{s}$ &
\end{tabular}

Table 2: Initial and boundary conditions, and other properties of the simulation.

\begin{tabular}{|c|c|c|}
\hline \multicolumn{2}{|l|}{ Boundary Conditions } & Reference \\
\hline Operating pressure & $101,325 \mathrm{~Pa}$ & \multirow{3}{*}{ (Coradi et al., 2016) } \\
\hline Solid moisture & 0.1558 b.u. & \\
\hline Air humidity & 0 & \\
\hline Solid temperature & $23^{\circ} \mathrm{C}$ & (Coradi; Lemes, 2019) \\
\hline Air temperature (inlet) & $90^{\circ} \mathrm{C}$ & (Coradi; Lemes, 2019) \\
\hline Air speed (inlet) & $0.35 \mathrm{~m} / \mathrm{s}$ & (Coradi; Lemes, 2019) \\
\hline \multicolumn{2}{|l|}{ Numeric properties } & References \\
\hline Heat transfer coefficient $(\mathrm{H})$ & $193.86 \mathrm{~W} / \mathrm{m}^{2} \mathrm{~K}$ & Eq. 1 \\
\hline Shrinkage rate $(\dot{r})$ & $1.09210^{-4} 1 / \mathrm{s}$ & (Coradi; Lemes, 2019) \\
\hline Sherwood Number $\left(\mathrm{Sh}_{\mathrm{q}}\right)$ & 1964.64 & Eq. 10 \\
\hline Mass transfer coefficient for the solid phase $\left(\mathrm{k}_{\mathrm{q}}\right)$ & $1.964610^{-8} \mathrm{~m} / \mathrm{s}$ & Eq. 7 \\
\hline Equilibrium Ratio $\left(\mathrm{K}_{\mathrm{qipi}}^{\mathrm{p}}\right)$ & $15,585.65$ & Eq. 9 \\
\hline Relaxation coefficients & $\begin{array}{c}\text { Pressure }=0.3 \\
\text { Momentum }=0.1 \\
\text { Energy }=0.1\end{array}$ & Costa, Peres and Petri (2021) \\
\hline Pressure & PRESTO! & \multirow{5}{*}{ Costa, Peres and Petri (2021) } \\
\hline Momentum & First Order Upwind & \\
\hline Energy & First Order Upwind & \\
\hline Pressure-Velocity coupling & SIMPLE & \\
\hline Multiphase model & Eulerian & \\
\hline
\end{tabular}

For the Constant model the water diffusivity in the solid did not influence the drying results, which suggests that the model defines mass transfer independently to some simulation parameters like: concentration gradient, species diffusivity, and temperature. This result suggests that the diffusive term is considered null, and that the model defines the mass transfer through the convective term only.

The moisture results over time for the three models (Constant, Species-Constant, Species-Sherwood) can be observed in Figure 5.

In order to better comprehend the behavior obtained for the Species models, the influence of the equilibrium ratio value was analyzed in two widely different values in Figure 6.

\subsubsection{Ranz-Marshall and Hughmark models}

With the Ranz-Marshall model for the calculation of the mass transfer coefficient for the solid phase, three tests with different conditions were made. Two simulations with an equilibrium ratio of 1,558.565: one using Ranz-Marshall for both phases, the other using Zero-Resistance for the air phase. The third simulation used Ranz-Marshall for both phases and an equilibrium ratio of 15,585.65.

Through these tests it was possible to observe the effects of both equilibrium ratio value and ZeroResistance modelling for the Ranz-Marshall model. The same was done for the Hughmark model, and the results of moisture over time for both models is presented in Figure 7. 


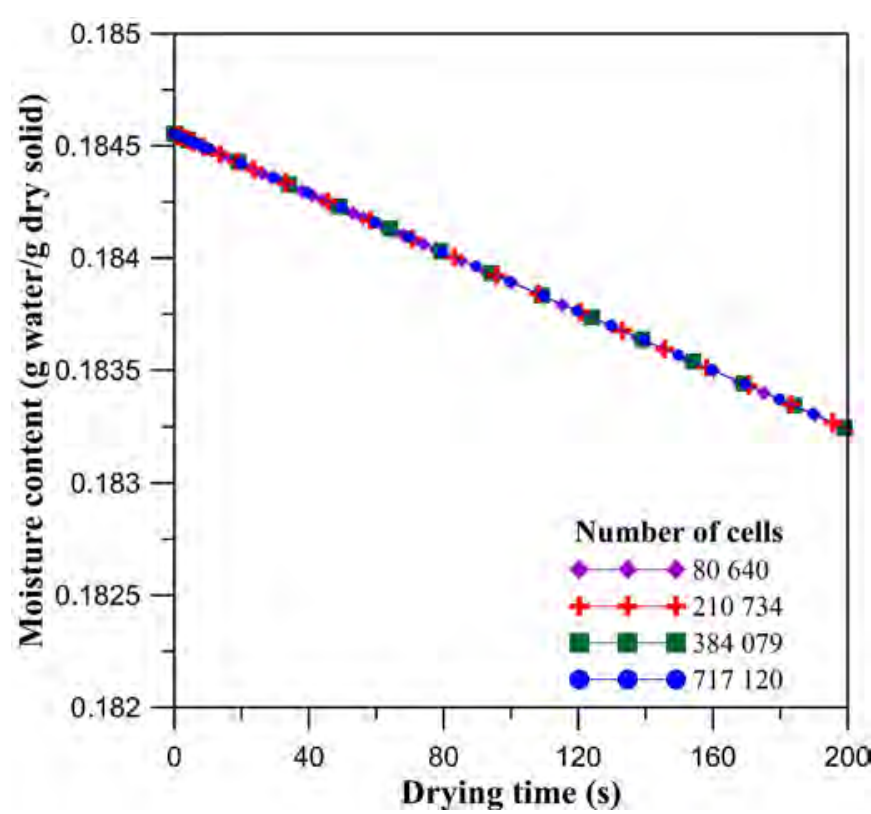

Figure 3: Moisture content for the mesh independence test.

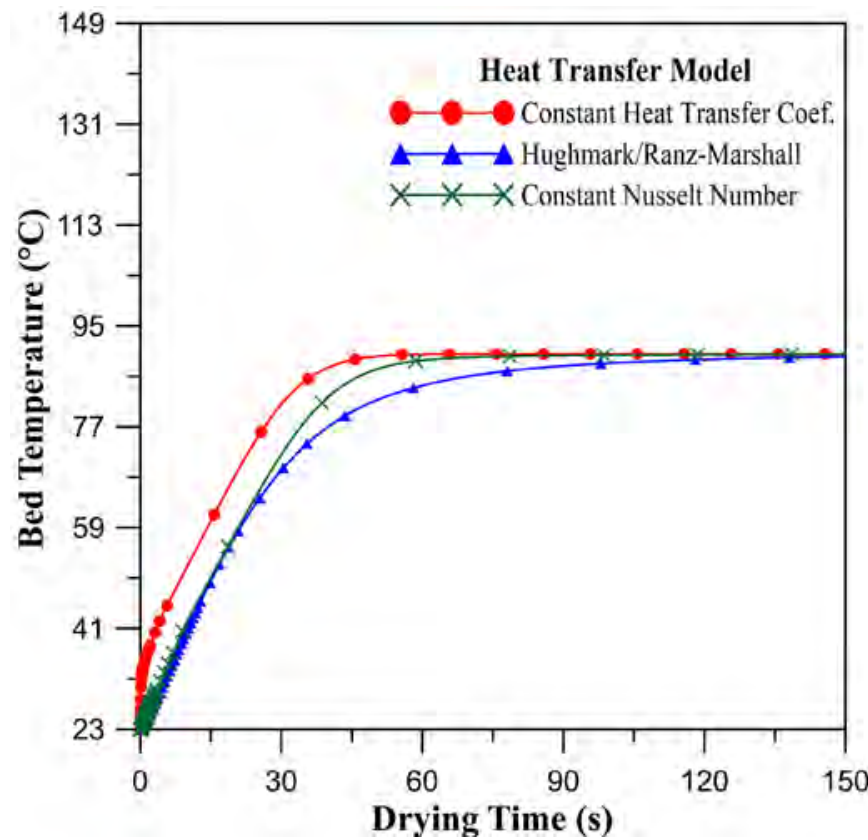

Figure 4: Particle heating kinetics for different heat transfer models.

Lastly, by comparing four different water diffusivities in the solid, $10^{-25}$ (approximately zero), $10^{-13}, 10^{-11}$, and $10^{-9}$ $\mathrm{m}^{2} / \mathrm{s}$, it was possible to observe its influence on the results using the Ranz-Marshall model. The drying over time using the four different diffusivities is shown in Figure 8.

\section{DISCUSSION}

In Figure 3 the behavior of the moisture did not change between the meshes. This indicates the meshes were sufficiently refined to monitor the moisture, and allows for the use of the less refined meshes tested, optimizing computational costs. Thus, the mesh used in this work was the mesh with 210,734 cells.

According to Figure 4, the behavior between the models was similar, with rapid heating overall, reaching thermal equilibrium at approximately two minutes. The Constant Heat Transfer Coefficient had the fastest heating, followed by Constant Nusselt Number, and lastly, Hughmark and Ranz-Marshall, which had analogous results and thus were presented together.

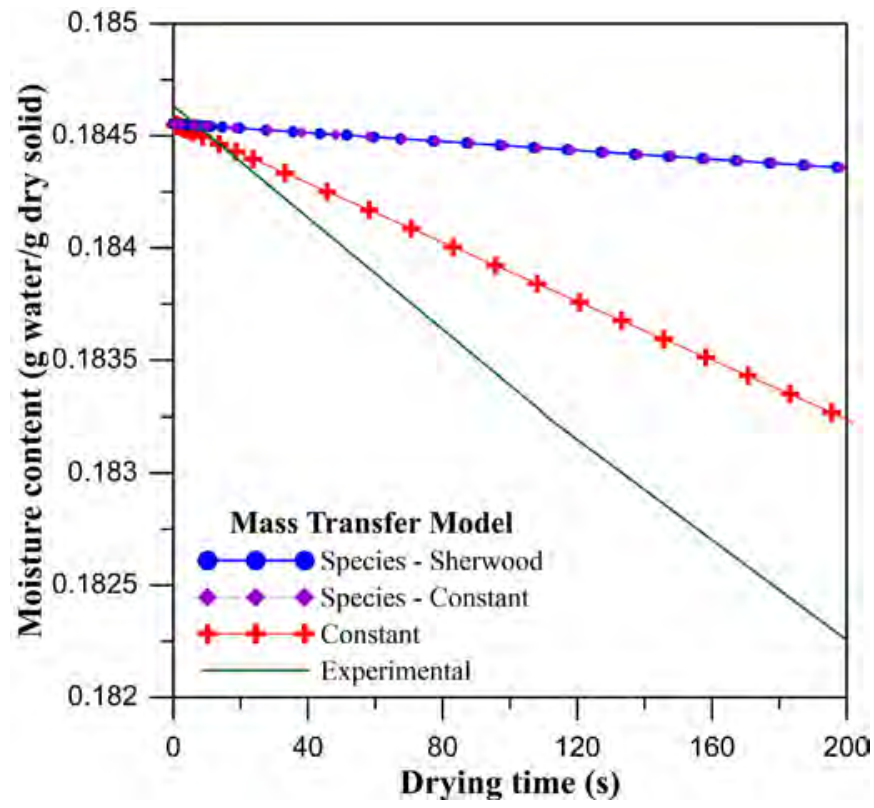

Figure 5: Moisture content for the Constant, Species-Constant, and Species-Sherwood models.

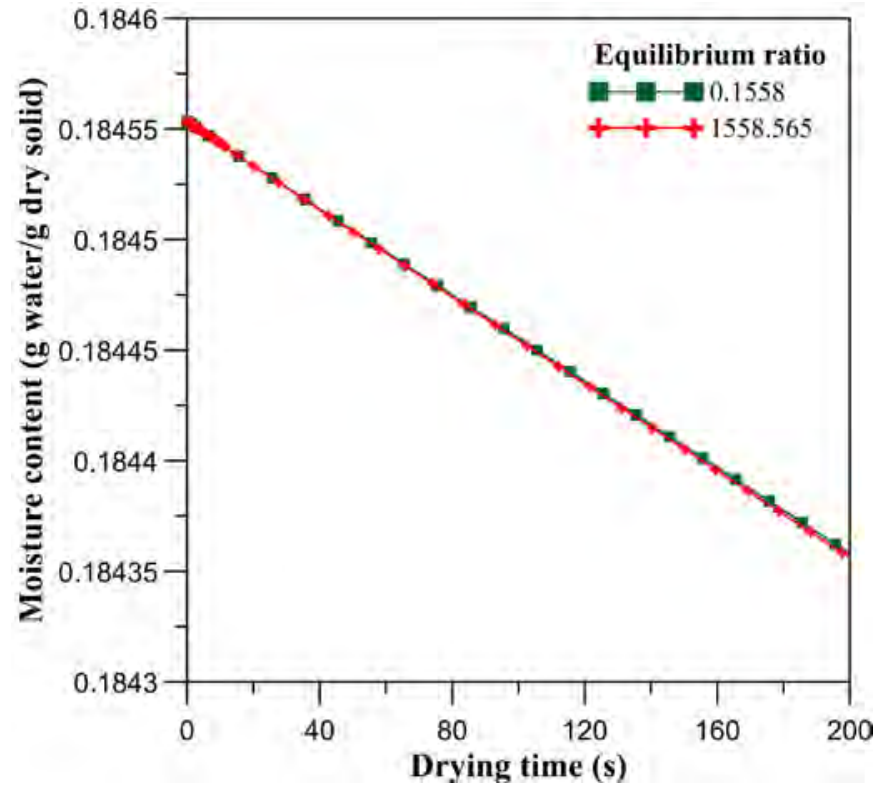

Figure 6: Moisture content for Species-Sherwood model with different equilibrium ratios. 


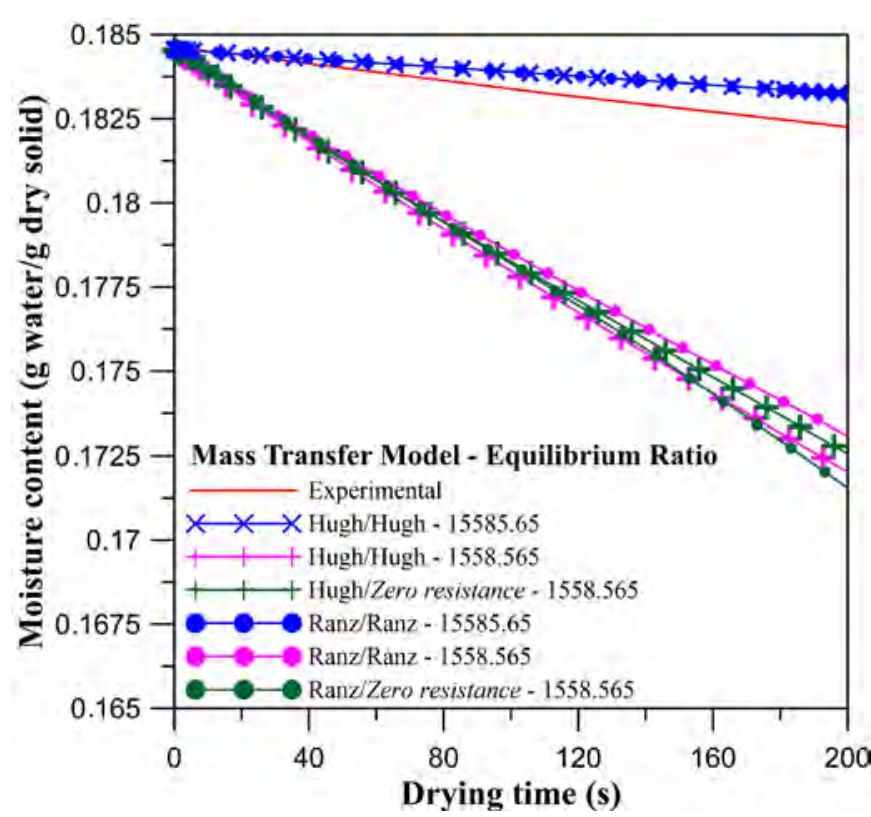

Figure 7: Moisture content for Ranz-Marshall, Hughmark and Zero-Resistance models with varying equilibrium ratios.

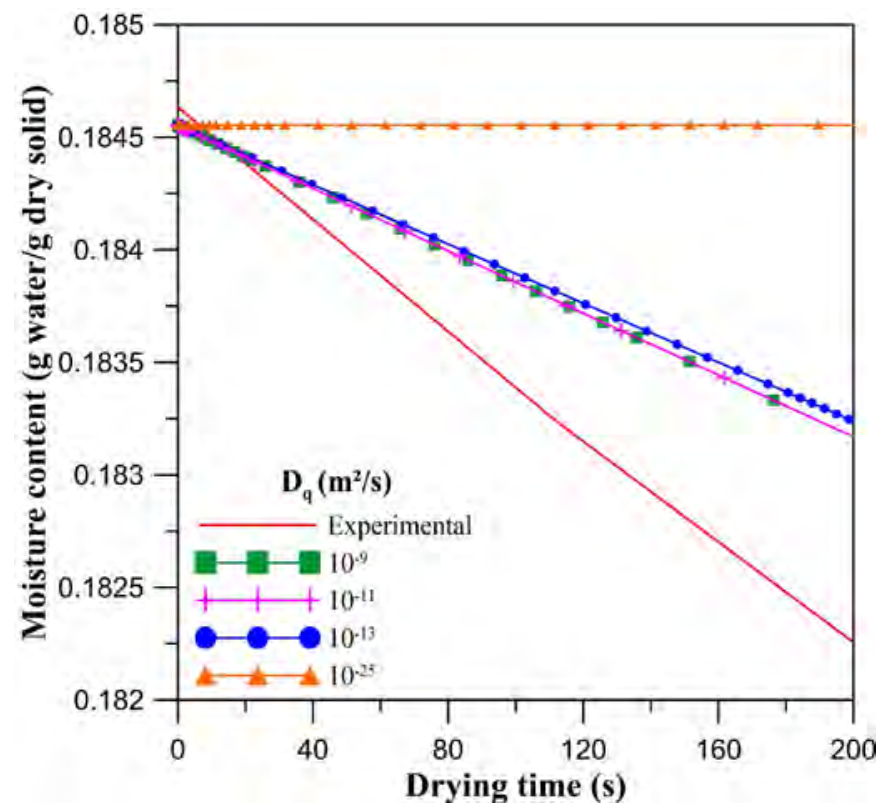

Figure 8: Moisture content for different water diffusivities in the solid for Ranz-Marshall model.

The results suggest that, even with changes of the heat transfer models, its behavior does not change substantially. In the following simulations the model used was the Constant Heat Transfer Coefficient, as it is the less complex model.

For delaying the heating, in order to reach more realistic results, the use of non-ideal boundary conditions for the walls would be efficient at simulating heat loss. The same rapid heating was observed for the Multiphase Eulerian Granular Model with packed bed configuration by Mateus and Petri (2021, in press).
Figure 5 shows that all three models underestimated the drying rate, showing higher moisture values than the experimental data. The Species-Constant and SpeciesSherwood had analogous results, while Species-Constant resulted in a higher drying rate. Thus, the Constant model was not enough to converge to the experimental results, even though it receives a direct input of the drying rate. The underestimation for models Species-Constant and Species-Sherwood can be explained through the surface area, which for the simulation is considered to be that of a sphere, therefore being smaller than the real surface area of the particle, which contains pores and imperfections. This directly impacts the mass transfer as stated by Equation 6, resulting in smaller drying rates.

According to Figure 6, changes in the equilibrium ratio did not affect the drying behavior for the model. This can be claimed for both Species-Sherwood and Species-Constant, considering both models are analogous, as seen in Equation 9.

In order to clarify the reason the equilibrium ratio does not affect the Species models, the Equation 8 provides a hypothesis. The Sherwood number and mass transfer coefficient values might have been small enough to make the equilibrium ratio value negligible to the volumetric mass transfer coefficient $\left(\mathrm{k}_{\mathrm{pq}}\right)$. This implies that the models are still sensible to the equilibrium ratio values, but only at specific values of Sherwood number, which might not be the case for the drying of seeds according to the results.

According to Figure 7, all four simulations with an equilibrium ratio of 1,558.56 had a significantly overestimated drying rate. For Ranz-Marshall, the usage of the ZeroResistance model increased the drying rate even more, which is concise, since the zero-resistance condition implies the strongest driving force for the mass transfer.

For Hughmark, the Zero-Resistance model reduced the drying rate. This result is inaccurate to what was expected, since it should consider the maximum concentration gradient at the interface, and indicates inconsistencies for the usage of the Zero-Resistance model with the Hughmark model.

The usage of an equilibrium ratio of 15,585.65 changed the results considerably, which were more approximate to the experimental result, but still underestimated the drying rate. This indicates a strong influence of the equilibrium ratio on the results of the Ranz-Marshall and Hughmark models. Thus, considering the equilibrium ratio is directly dependent on the moisture values, its usage through an UDF, that is, a varying property, would improve the representativeness of the simulation.

According to Figure 8, less intense changes on the diffusivity did not considerably affect the drying results. However, for a diffusivity of approximately zero $\left(10^{-25} \mathrm{~m}^{2} / \mathrm{s}\right)$, the drying was null, which implies that the diffusivity does affect both the diffusive and convective mass transfer for the Ranz-Marshall model. 


\section{CONCLUSIONS}

The Species-Constant and Species-Sherwood models had analogous behavior, while the Constant model better approximated to the experimental results. All three models still underestimated the drying rate, presenting superior moisture values to the experimental values. This could be explained by the surface area of the simulation, which considered the area of a sphere without pores and imperfections, thus significantly underestimating the surface area and consequently the mass transfer.

The water diffusivity in the solid did not influence the drying of the Constant model, suggesting it ignores the diffusive mass transfer, defining it only through the convective term. Changes to the equilibrium ratio for Species-Constant and Species-Sherwood models did not influence the results, which might happen only for small values of Sherwood number or mass transfer coefficient.

The Ranz-Marshall and Hughmark models showed the best proximity to the experimental results, and had analogous behavior for similar equilibrium ratios. The usage of the ZeroResistance model for the air phase increased the mass transfer for the Ranz-Marshall model, while for Hughmark, the drying rate decreased. This result for Hughmark is inconsistent, and is not representative of a zero-resistance condition. Both models had high sensitivity for changes in the equilibrium ratio, which implies that the system would benefit from a modelling where the equilibrium ratio varies accordingly to the moisture changes of the system. This could be done with UDFs.

The Ranz-Marshall model was not considerably influenced by the water diffusivity in the solid value. Still, this relation should be further investigated, since for a diffusivity of approximately zero, the mass transfer was null. This suggests the mass transfer for the model in question is defined by both diffusive and convective mass transfer.

Thus, it can be highlighted that the Constant, SpeciesConstant and Species-Sherwood models were limited for the simulation of the dryer, and that the equilibrium ratio is a fundamental property for the Ranz-Marshall and Hughmark models, which better converged to the experimental results.

\section{ACKNOWLEDGEMENTS}

This work was supported by the, Foundation for Research Support of Minas Gerais (FAPEMIG) project number APQ-00036-21, National Council for Scientific and Technological Development $(\mathrm{CNPq})$ project number 427962/2018-8 and Federal University of Lavras (UFLA) project numbers PIDEG357-2018 and PIDEG76-2018, the authors are grateful to the for their financial support. Special thanks to the professors and technician from Coffee Innovation Agency of UFLA.

\section{REFERENCES}

ANSYS. Fluent User's Guide and Theory Guide. Canonsburg: [s.n.], 2018. Available in: <https://ansyshelp. ansys.com>. Access in: October, 30, 2020.

AZADBAKHT, M. et al. Thermal properties of soybean pod as a function of moisture content and temperature. American journal of food science and technology, 1(2):9-13, 2013.

BERGMAN, T. L. et al. Introduction to heat transfer. Jefferson City: John Wiley \& Sons, 2011. 960p.

CORADI, P. C. et al. Effects of drying air temperature and grain initial moisture content on soybean quality (Glycine max (L.) Merrill). Engenharia Agrícola, 36(1): 866-876, 2016.

CORADI, P. C. et al. Mathematical modeling of drying in a new concept of silo-dryer-aerator and the quality of soybean seeds (Glycine max (L.) Merrill). Journal of Agricultural Science and Technology B, 8(1):483-498, 2018.

CORADI, P. C.; LEMES, Â. F. C. Experimental prototype of silo-dryer-aerator of grains using Computational Fluid Dynamics (CFD) system. Acta Scientiarum. Technology, 41:e36949, 2019.

COSTA, F. O.; PERES, A. P.; PETRI JUNIOR, I. Simulation of hydrocyclones for evaluating the flow of nonNewtonian fluids. Revista de Engenharia e Tecnologia, 13(1):1-12, 2021.

DESHPANDE, S. D.; BAL, S.; OJHA, T. P. Physical properties of soybean. Journal of Agricultural Engineering Research, 56(2):89-98, 1993.

GARCIA, D. C. et al. Seed drying. Ciência Rural, 34(2):603-608, 2004.

HUGHMARK G. A. T. I. Mass and heat transfer from rigid spheres. AIChE Journal, 13(6):1219-1221, 1967.

KLOSS, C. et al. Models, algorithms and validation for opensource DEM and CFD-DEM. Progress in Computational Fluid Dynamics, an International Journal, 12(2-3):140-152, 2012.

MADAMBA, P. S.; DRISCOLL, R. H.; BUCKLE, K. A. Thin-layer drying characteristics of garlic slices. Journal of Food Engineering, 29(1):75-97, 1996.

MATEUS, F. L. B.; PETRI, I. J.; Momentum and heat transfer prediction in a silo-dryer through computational fluid-dynamics. Coffee Science, 16:e161902, 2021. 
MCCABE, W. L.; SMITH, J. C.; HARRIOTT, P. Unit operations of chemical engineering. New York: McGraw-hill, 1993. 175p.

RANZ, W. E.; MARSHALL, W. R. Evaporation from drops. Chemical Engineering Progress, 48(1):137152, 1952.

REINATO, C. H. R. et al. Energy consumption and costs in coffee drying of agricultural properties from the south of Minas Gerais. Revista Brasileira de Engenharia Agrícola e Ambiental, 6(1):112-116, 2002.
STOPPE, A. C. R.; NETO, J. L. V.; DOS SANTOS, K. G. Development of a fixed bed solar dryer: experimental study and CFD simulation. Research, Society and Development, 9(3):e123932667, 2020.

SZAFRAN, R. G.; KMIEC, A. CFD modeling of heat and mass transfer in a spouted bed dryer. Industrial \& Engineering Chemistry Research, 43(4):1113-1124, 2004.

XIA, B.; SUN, D-W. Applications of computational fluid dynamics (CFD) in the food industry: a review. Computers and Electronics in Agriculture, 34(1-3):5-24, 2002. 